DOI: $10.2478 / \mathrm{v} .10169-012-0027-7$

\title{
NONLINEAR STATIC ANALYSIS OF AN ASPHALT CONCRETE CORE DAM FOR COMPARISON OF THREE CONSTITUTIVE MODELS
}

\author{
Z. $\mathrm{HONG}^{1}$, Z. HONGYAN ${ }^{1}$, D. JIANKE ${ }^{2}$
}

\begin{abstract}
The goal of this work is to compare different constitutive models in the nonlinear static characteristic analysis of asphalt concrete core dams. The Duncan E- $\mu$ model, Duncan E-B model and double-yield-surface model are three major constitutive models in the nonlinear static prediction of earth-rockfill dam. In this paper, an earth-rockfill dam with asphalt concrete core-wall in an actual hydraulic engineering is employed to compare the three models. The finite element model of the core-wall dam is proposed. Nonlinear static analysis of the dam is carried out and the static characteristics are obtained to study the differences generated from different constitutive models. Numerical results show that both the stress extremum and the stress distribution of dam body with three different models are coincident one another. In the deformation analysis of dam body and core-wall, the maximum values of sedimentation with the Duncan E- $\mu$ model and the Duncan E-B model, which are greater than the value with double-yield-surface model, are close to the practical test data though the deformation distributions with three models are in good agreement. But, the analysis results of core-wall stress with double-yield-surface model are proper and more reasonable than the other models.
\end{abstract}

Key words: dam, asphalt concrete core-wall, constitutive model, Duncan model, double-yield-surface model.

\section{INTRODUCTION}

The earth-rockfill dam has many significant advantages, such as simple construction, low cost, long life, wide adaptability of topographic and geologic conditions, and so on. It has become a major dam type in current hydraulic engineering. The traditional impermeable material for an earth-rockfill dam is based on the clay. On account of the rigorous requirements for clay gradation, the great effects of the local climate on clayey execution, and the demands of soil conservation and environment protection, selecting an appropriate impermeable material is increasingly difficult. This restricts the development of clayey soil dam objectively. The application of asphalt concrete materials as the impermeable material of the dam began in the 1930's. As the asphalt

\footnotetext{
1 The key Laboratory of pavement materials of Ministry of Education, School of Science, Chang'an University, 710064, Xi' an, China

${ }^{2}$ School of Mechanical Engineering and Mechanics, Ningbo University, 315211, Ningbo, China
} 
concrete spreading and rolling machinery was successfully developed in 70 years of the 20th century, the earth-rockfill dam with asphalt concrete core-wall has been a rapid development in water resources and hydroelectric power engineering [1-3].

At present, constitutive models mostly used for the numerical simulation of the behavior of soils and rocks are nonlinear elastic models and elasto-plastic models. Nonlinear elastic models represented by the Duncan E- $\mu$ model [4] and the Duncan E-B model [5] are directly constructed by fitting the test stress-strain curve of soils. These models have been widely used in practical engineering since their parameters possess clear physical meanings and can be easily obtained from test. On the other hand, Elasto-plastic models, such as the Modified Cam-clay model [6,7], the Nanshui double-yield- surface model and the Yin Zongze yield surface model [3, 8], can describe comprehensively characteristics of soils including pressure hardening, nonlinearity, dilatancy and stress-induced anisotropy.

To ensure the safe working of the dam, it is crucial to predict the stress and strain response of the dam and the core-wall accurately. The simulations and analysis about the earth-rock fill dam with clay core-wall or rockfill dam with concrete face plates have been carried out by many researchers [3, 9-11]. With the Duncan E-B model, Cam-clay model and Nanshui double-yield-surface model, SHEN and WANG [8] have analyzed and compared the stresses and strains distributions of Hengshan Reservoir dam. Wu et al. [9] have simulated the concrete face rock-fill dam filling process by three-dimensional nonlinear finite element method and some numerical results were obtained. A three-dimensional numerical study of a hypothetical CFRD was presented by Frutuoso et al. [10] in order to verify the influence of the valley shape on the embankment behavior. In their model, the linear elastic constitutive model was adopted to describe the behavior of the foundation and the Cam clay elasto-plastic constitutive model was adopted for the rockfill materials and interface between the rockfill embankment and the slope of the valley. WANG et al. [11] have studied the settlement behaviors of Shuibuya concrete faced rockfill dam at the construction and impounding stages. In their analysis, the rockfill material was modeled by the double yield surfaces model according to the actual material zoning and construction procedure of the dam. The maximum settlement and horizontal displacement of the rockfill part and the deflection and downslope displacement of face slabs were obtained and analyzed, respectively.

As to asphalt concrete core dams, some research works have been done, and in these works nonlinear elastic model and elasto-plastic model are the two common used models. WANG and HöEg [12] investigated the behavior of hydraulic asphalt specimens subjected to cyclic loading in a triaxial cell. The specimens were tested at various sustained static stress states and temperatures and at maximum cyclic shear stress levels corresponding to severe earthquake shaking of the dam. FeIzI-KHAnKandi et al. [13] studied seismic behavior of a rockfill dam with asphalt concrete core. The different stages of construction and impounding were analyzed with the Duncan model and the 2D nonlinear dynamic analyses were performed to investigate asphaltic core behavior under earthquake loading. The Duncan model was adopted by Chaoyang et al. 
[14] to compute the stress and strain of both the rockfill dam and the asphalt-concrete core after karst grouting and other treatments. However, few published documents exist on the comparison of different constitutive models in characteristics predictions of the asphalt concrete core dam. There is a strong lack of profound understanding the difference among the nonlinear strength property of asphalt concrete core dam with different constitutive models. For this purpose, the three-dimensional finite model of a practical asphalt concrete core dam has been founded. Nonlinear static property predictions of the dam are performed with three classical constitutive models and the distribution and extreme values of stresses and strains are studied in order to compare the differences generated from different constitutive models.

\section{Three CONSTITUTIVE MODELS}

The Duncan E- $\mu$ model, Duncan E-B model and double-yield-surface model are three major constitutive models in the nonlinear static prediction of asphalt concrete core dam. Although the three models are not very appropriate for asphalt, they have been widely used in practical engineering to simulate the mechanical behavior of asphalt due to their simple form and parameters are easily getting from the test.

\subsection{Duncan E- $\mu$ MOdeL}

According to Konder's postulation which indicates that the test curve between deviatonic stress and axial strain in triaxial test of soils is similar to hyperbolic curve, Duncan and ZHANG [4] have presented the E- $\mu$ model. Initially, the model is only applicable to two dimensional problems. Later, in order to solve three dimensional problems, it was amended by replacing the stress $\sigma_{3}$ with the average principal stress $p$ and replacing $\left(\sigma_{1}-\sigma_{3}\right)$ with generalized shear stress $q$.

$$
\begin{gathered}
p=\frac{1}{3}\left(\sigma_{1}+\sigma_{2}+\sigma_{3}\right) \\
q=\sqrt{\frac{1}{2}\left[\left(\sigma_{1}-\sigma_{2}\right)^{2}+\left(\sigma_{2}-\sigma_{3}\right)^{2}+\left(\sigma_{1}-\sigma_{3}\right)^{2}\right]}
\end{gathered}
$$

On the assumption that shear strength of rocks complies with the Mohr-Coulomb failure criterion, the expression of the tangent elastic modulus $E_{t}$ can be written as

$$
E_{t}=E_{i}\left(1-R_{f} S_{l}\right)^{2}
$$

where $R_{f}$ is a material parameter called the damage ratio. $E_{i}$ is the initial tangent elastic modulus and it can be obtained by using the empirical Janbu formula [15]

$$
E_{i}=K P_{a}\left(p / P_{a}\right)^{n}
$$


in which $P_{a}$ is the atmospheric pressure. $S_{l}$ in Eq. (2.3) is the stress level and it can be calculated by

$$
S_{l}=\frac{q}{q_{f}}
$$

By using the Mohr-Coulunb criterion, we can get

$$
\begin{gathered}
q_{f}=\frac{3 c \cos \phi+3 p \sin \phi}{\sqrt{3} \cos \theta_{\sigma}+\sin \phi \sin \theta_{\sigma}} \\
S_{l}=\frac{q\left(\sqrt{3} \cos \theta_{\sigma}+\sin \phi \sin \theta_{\sigma}\right)}{3 c \cos \phi+3 p \sin \phi}
\end{gathered}
$$

where $c$ is the cohesion force, $\phi$ is the internal friction angle and $\theta_{\sigma}$ is the Lode stress angle.

According to Kulhawy and Duncan's proposition, the Poisson's ratio $\mu_{t}$ in the Duncan E- $\mu$ model can be obtained from the approach of getting the tangent Poisson's ratio from the triaxial test data of soils.

$$
\mu_{t}=\frac{G-F \log \left(p / P_{a}\right)}{\left[1-\frac{D q}{E_{i}\left(1-R_{f} S_{l}\right)}\right]^{2}}
$$

In above equations, $K, n, R_{f}, C, \phi, G, F$ and $D$, which are eight nonlinear stress-strain parameters of the E- $\mu$ model, can be determined using the triaxial test of soils.

\subsection{Duncan E-B Model}

Using tangent bulk modulus instead of tangent Poisson's ratio, Duncan et al. [5] developed the Duncan E-B model. Similarly, the Duncan E-B model was extended to three-dimensional problems by replacing the stress $\sigma_{3}$ with the average principal stress $p$ and replacing $\left(\sigma_{1}-\sigma_{3}\right)$ with generalized shear stress $q$. The tangent elastic modulus of the E-B model is also defined by Eq. (3) and tangent bulk modulus $B_{t}$ is given by

$$
B_{t}=K_{b} P_{a}\left(\frac{p}{P_{a}}\right)^{m}
$$

where $K_{b}$ and $m$ are model parameters. Thus, the Poisson's ratio can be expressed as

$$
\mu_{t}=\frac{1}{2}\left(1-\frac{E_{t}}{3 B_{t}}\right)=\frac{1}{2}\left[1-\frac{\left(1-R_{f} S_{l}\right)^{2}}{3 K_{b}}\left(\frac{p}{P_{a}}\right)^{n-m}\right]
$$

In above equations, $K, n, R_{f}, C, \phi_{1}, \Delta \phi, K_{b}$ and $\mathrm{m}$ are nonlinear stress-strain parameters of the Duncan E-B model and they also can be obtained by triaxial test of soils. 


\subsection{DoubLE-YIELD-SURFACE MODEL}

Based on the double yield surface theory, SHEN et al. [8] proposed the double-yield-surface model in which the yield function has the following form

$$
\left.\begin{array}{c}
f_{1}=p^{2}+r^{2} q^{2} \\
f_{2}=q^{s} / p
\end{array}\right\}
$$

where $r$ and $s$ are yield surface parameters. The corresponding plastic volume strain and shear strain can be calculated by the following equations

$$
\begin{gathered}
\Delta v^{p}=\left(\frac{A_{1}}{r^{2}}+\eta^{2} A_{2}\right) \Delta p+\eta\left(A_{1}-A_{2}\right) \Delta q \\
\Delta \gamma^{p}=\frac{2}{3}\left[\eta\left(A_{1}-A_{2}\right) \Delta p+\left(r^{2} \eta^{2} A_{1}+A_{2}\right) \Delta q\right]
\end{gathered}
$$

where plastic coefficients $A_{1}$ and $A_{2}$ are

$$
\begin{gathered}
A_{1}=r^{2}\left(\eta E_{1}+\sqrt{2} s E_{2}\right) / \sqrt{2}\left(s+r^{2} \eta^{2}\right)\left(1+\sqrt{2} r^{2} \eta\right) \\
A_{2}=\left(E_{1}-\sqrt{2} r^{2} \eta E_{2}\right) / \sqrt{2}\left(s+r^{2} \eta^{2}\right)(\sqrt{2} s-\eta)
\end{gathered}
$$

and

$$
E_{1}=9 / E_{t}-3 \mu_{t} / E_{t}-3 / G_{s}, \quad E_{2}=3 \mu_{t} / E_{t}-1 / B
$$

In above equation, $E_{t}$ has the same expression with Eq. (2.3) of Duncan E- $\mu$ model. $\mu_{t}$ can be obtained by the following equation

$$
\mu_{t}=2 c_{d}\left(\frac{p}{P_{a}}\right)^{d} \frac{E_{1} R_{s}}{\sigma_{1}-\sigma_{3}} \frac{1-R_{d}}{R_{d}}\left(1-\frac{R_{s}}{1-R_{s}} \frac{1-R_{d}}{R_{d}}\right)
$$

where $R_{s}=R_{f} \cdot S_{l} \cdot c_{d}, n_{d}$ and $R_{d}$ are model parameters.

The double-yield-surface model involves a total of 9 parameters, which are $K, K_{u r}$, $n, R_{f}, C, \phi, c_{d}, n_{d}$ and $R_{d}$, respectively. The first six parameters have the same meanings with those of the Duncan model and the last three parameters can be obtained from the volumetric strain curve of the triaxial test of soils or derived from parameters $G$, $F$ and $D$ of the Duncan E- $\mu$ model. 


\section{Three Dimensional FINITE ELEMENT MODEL}

In this section, an earth-rockfill dam with asphalt concrete core-wall in an actual hydraulic engineering is employed to analyze its nonlinear static characteristics. With three different constitutive models shown in section 2, stress and deformation characteristics of the dam and the core-wall are studied and compared.

The elevations of the dam crest and the top of the core-wall are $657.00 \mathrm{~m}$ and $656.50 \mathrm{~m}$, respectively, and the height of the core wall is $62.30 \mathrm{~m}$. During the constructing of the dam, the first and second phases of the cofferdam were filled at first, and then the dam was built layer by layer. Two transition layers with $3 \mathrm{~m}$ in width are located in each side of the core-wall, respectively.

As shown in Fig. 1, the three dimensional finite element model of the asphalt concrete core dam is established. The dam and the core-wall are subdivided using spatial tetrahedron elements and brick elements, respectively. Contact elements are used to simulate the contact interaction among the core-wall, transition layers and the concrete foundation. The finite element model of the whole dam comprises 22, 127 nodes and 109, 190 elements including 2, 421 contact elements. Figure 2 plots the finite element model of the asphalt concrete core-wall and the global coordinate system, in which the $\mathrm{x}$-axis parallels to the direction of the stream, the $\mathrm{y}$-axis is along the direction of the altitude and the $\mathrm{z}$-axis refers to the axial line of the dam.

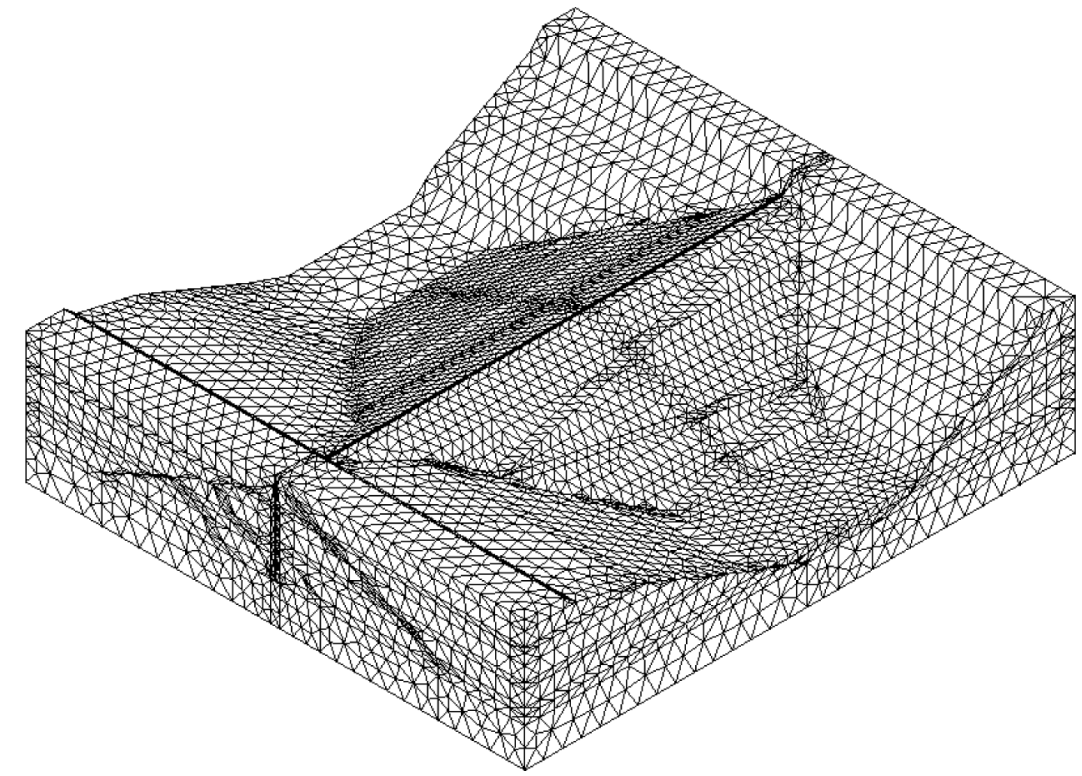

Fig. 1. Three dimensional finite element model of the asphalt concrete core dam with its foundation.

The materials used in the calculation mainly involve asphalt concrete of the core-wall, transition materials, dam shell gravel, rock and concrete of the dam base. The 


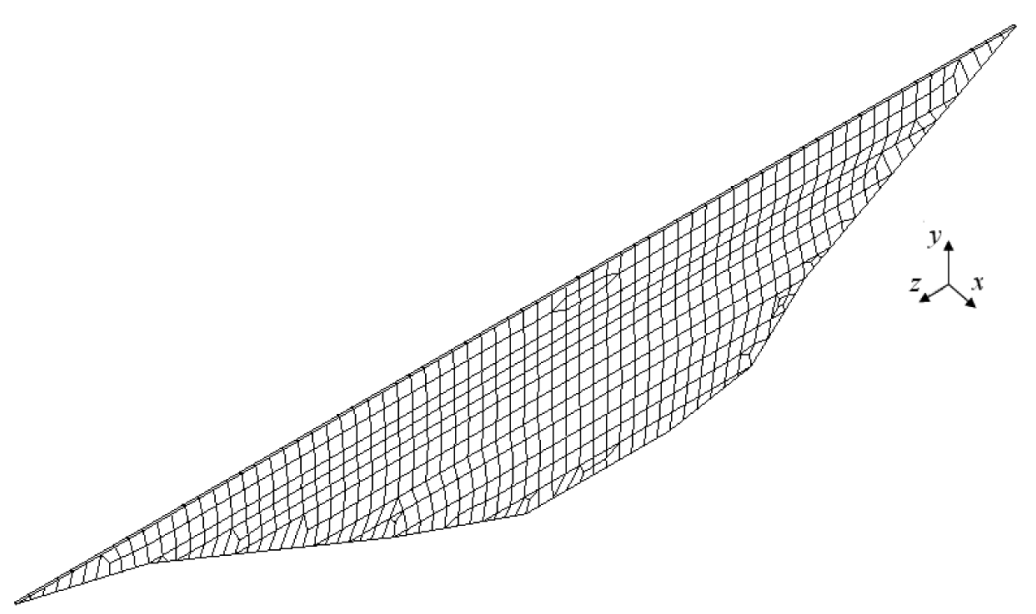

Fig. 2. Finite element model of the asphalt concrete core wall.

Duncan E- $\mu$ model, Duncan E-B model and double-yield-surface model are adopted to describe nonlinear constitutive relationships of the asphalt concrete of the core-wall and dam materials, respectively. The related model parameters are determined by the triaxial test of the actual sample materials, as shown in Table 1 . The rock and concrete of the dam base is modeled by linear elastic constitutive model.

Table 1

The model parameters of the asphalt concrete core dam.

\begin{tabular}{|c|c|c|c|c|c|c|c|}
\hline \multirow{2}{*}{ Materials } & \multicolumn{7}{|c|}{ Calculation parameters in common } \\
\cline { 2 - 8 } & $R_{f}$ & $K$ & $n$ & $K_{b}$ & $c / \mathrm{MP}_{a}$ & $\phi$ & $K_{u r}$ \\
\hline Asphalt concrete & 0.72 & 273 & 0.28 & 1663 & 0.240 & 26.9 & 1600 \\
\hline Dam shell materials & 0.81 & 644 & 0.37 & 241 & 0.046 & 45.4 & 902 \\
\hline Transition material & 0.90 & 950 & 0.39 & 588 & 0.045 & 47.44 & 1520 \\
\hline
\end{tabular}

\begin{tabular}{|c|c|c|c|c|c|c|c|}
\hline \multicolumn{3}{|c|}{ Duncan E- $\mu$ model } & \multicolumn{2}{c|}{ Duncan E-B model } & \multicolumn{3}{c|}{ Double-yield-surface model } \\
\hline$G$ & $F$ & $D$ & $K_{b}$ & $m$ & $c_{d}$ & $n_{d}$ & $R_{d}$ \\
\hline 0.48 & 0 & 0 & 1663 & 0.27 & 0.016 & 0.47 & 0.70 \\
\hline 0.41 & 0.08 & 1.44 & 241 & 0.34 & 0.0031 & 1.03 & 0.81 \\
\hline 0.47 & 0.09 & 1.48 & 588 & 0.18 & 0.0014 & 1.12 & 0.86 \\
\hline
\end{tabular}

In order to simulate the processes of the dam constructing and water storing, two work conditions, the constructing stage and the impounding stage, are considered here. Loads are applied step by step and a total of 23 load steps are involved during the calculation process. To ensure the precision in calculation, the increment method is used in each substep, while the contact relationships among the asphalt concrete of the 
core-wall, transition materials and the concrete of the base are implemented through Newton-Raphson iterative technique.

\section{NumericAl RESUlts AND DISCUSSION}

Using different constitutive models, the calculated maximum sedimentation displacements of the dam after its final completion are $0.2307 \mathrm{~m}$ with the $\mathrm{E}-\mu$ model, $0.2404 \mathrm{~m}$ with the E-B model and $0.1251 \mathrm{~m}$ with the double-yield-surface model, respectively. It is apparent that the maximum displacement obtained from the $\mathrm{E}-\mu$ model is close to that obtained from the E-B model, while the maximum displacement got from the double-yield-surface model is significantly less than that of the first two models. According to the practical measured data, which is approximate to $0.30-0.35 \mathrm{~m}$, the maximum sedimentation displacements calculated from the E- $\mu$ model and E-B model are reasonable, while the maximum displacement obtained from the double-yield-surface is too small. The coordinates of the maximum sedimentation displacements obtained from the three models are $(0.40,633.50,142.43),(11.29,633.50,169.56)$ and $(10.23,633.50$, 161.58), respectively. That is, it is at about $2 / 3$ altitude of the dam and close to the midpoint of the axial line of the dam. Figure 3 shows the sedimentation displacement distribution of the highest profile of the dam. Although the amplitudes of the maximum sedimentation obtained from the three models are different, the sedimentation distributions are quite similar and the positions where the maximum displacements occur are almost the same.

Figure 4 illustrates the compressive stress distribution of the highest dam profile. It is readily shown that, with different constitutive models, compressive stress distributions described in the three diagrams are similar, but the maximum stress got from the double-yield-surface model is less than others. The maximum major principle stress after the final completion of the dam is $1.9552 \mathrm{MPa}$ by the $\mathrm{E}-\mu$ model, $1.8423 \mathrm{MPa}$ by the E-B model and $1.7454 \mathrm{MPa}$ by the double-yield-surface model. The corresponding coordinates are $(-0.40,599.50,134.00),(-0.40,594.20,123.00)$ and $(2.70,601.33$, 92.01), respectively. It is notable that there is no tension stress appearing in the major principle stress distribution of the double-yield-surface model. The maximum minor principle stress of the dam is $0.9925 \mathrm{MPa}$ with the E- $\mu$ model, $1.0594 \mathrm{MPa}$ with the E-B model and $0.7500 \mathrm{MPa}$ with the double-yield-surface model. The maximum tension stress appearing in the minor principle stress calculated by the double-yield-surface model is only $0.0623 \mathrm{Mpa}$, which is less than those obtained from the E- $\mu$ model and the E-B model that are $0.4941 \mathrm{MPa}$ and $0.5755 \mathrm{MPa}$, respectively. All of these tension stresses occur in the contact area between the transition materials and the core-wall. The maximum vertical compressive stresses obtained from the three models are listed in Table 2, in which the DYS model is defined as the double-yield-surface model. It is noted that the maximum compressive stresses calculated from the E- $\mu$ model and the E-B model appear at the contact region between transition materials and the core-wall. 


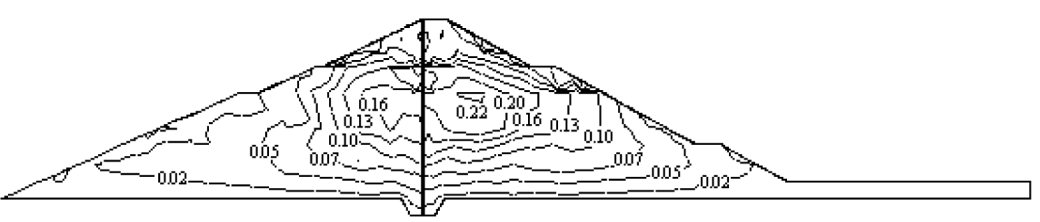

(a) E- $\mu$ model

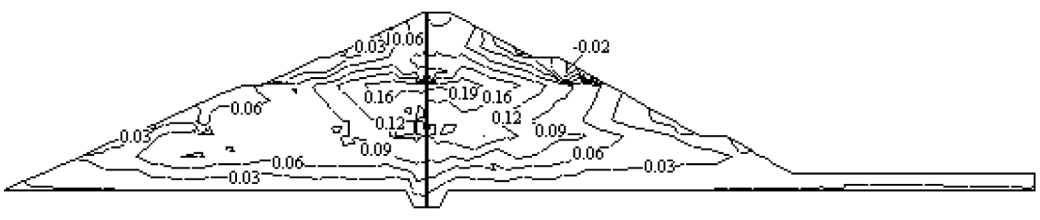

(b) E-B model

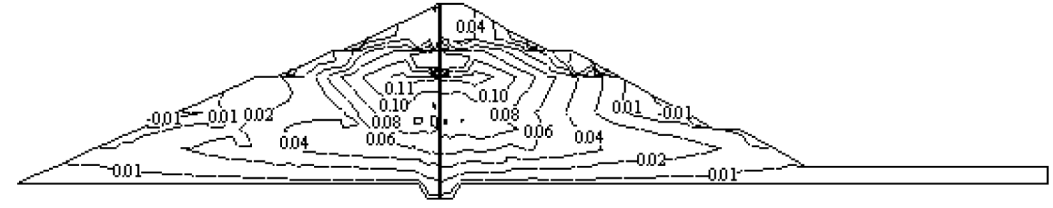

(c) Double-yield-surface model

Fig. 3. Sedimentation distribution of the highest dam profile after completion (m).

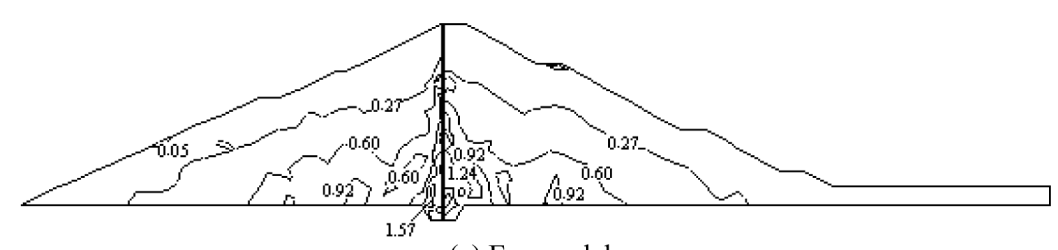

(a) E- $\mu$ model

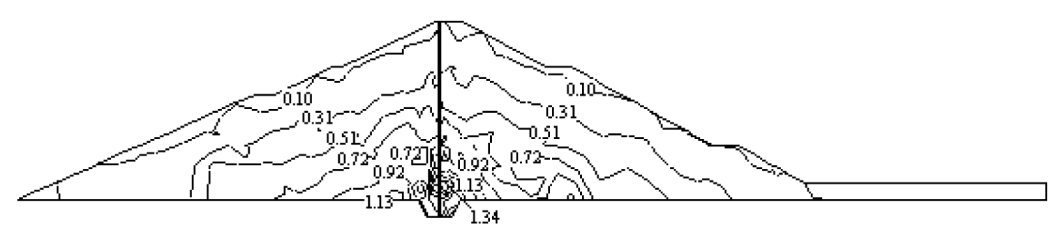

(b) E-B model

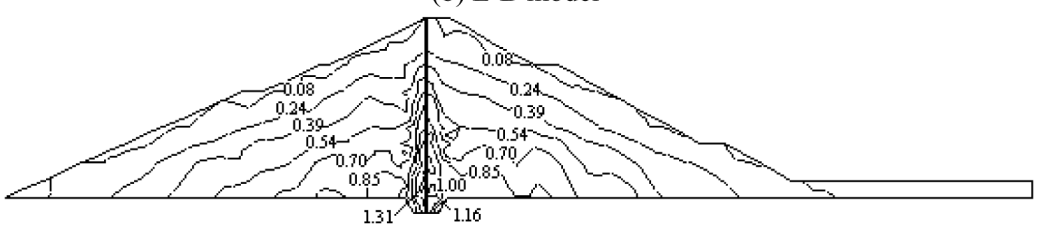

(c) Double-yield-surface model

Fig. 4. Compressive stress distribution of the highest dam profile after completion (MPa). 
Locations and stress components of the maximum vertical stresses of the dam.

\begin{tabular}{|c|c|c|c|c|c|c|c|c|}
\hline $\begin{array}{l}\text { Working } \\
\text { condition }\end{array}$ & models & Locations & $S_{x}$ & $S_{y}$ & $S_{z}$ & $\tau_{x y}$ & $\tau_{y z}$ & $\tau_{x z}$ \\
\hline \multirow{3}{*}{$\begin{array}{c}\text { After } \\
\text { completion }\end{array}$} & E- $\mu$ model & $\begin{array}{c}x=-0.4 \\
y=599.5 \\
z=110.0\end{array}$ & -0.5117 & -1.9464 & -0.5921 & 0.0173 & -0.0442 & 0.0683 \\
\hline & E-B model & $\begin{array}{c}x=-0.4 \\
y=599.5 \\
z=134.0\end{array}$ & -0.5031 & -1.8404 & -0.5783 & 0.0139 & 0.0415 & 0.0014 \\
\hline & DYS model & $\begin{array}{c}x=2.5 \\
y=613.8 \\
z=176.5\end{array}$ & -0.2937 & -1.6678 & -0.6957 & -0.0018 & 0.0099 & 0.0017 \\
\hline \multirow{3}{*}{$\begin{array}{l}\text { After impound- } \\
\text { ment }\end{array}$} & E- $\mu$ model & $\begin{array}{c}x=2.3 \\
y=600.6 \\
z=192.5\end{array}$ & -0.7000 & -1.3747 & -0.8113 & 0.1787 & 0.0781 & -0.0655 \\
\hline & E-B model & $\begin{array}{c}x=0.4 \\
y=599.5 \\
z=110.0\end{array}$ & -0.5876 & -1.5236 & -0.5522 & 0.1974 & 0.0663 & 0.0149 \\
\hline & DYS model & $\begin{array}{c}x=-0.4 \\
y=601.7 \\
z=195.6\end{array}$ & -0.5316 & -1.3552 & -0.5310 & -0.2738 & 0.0858 & -0.0926 \\
\hline
\end{tabular}

Note: Stress is positive in tension and negative in compression.

The maximum sedimentation of the core-wall is $0.2138 \mathrm{~m}$ with the E- $\mu$ model, $0.1960 \mathrm{~m}$ with the E-B model and $0.1209 \mathrm{~m}$ with the double-yield-surface model. The maximum sedimentations of the core-wall calculated with the three models are all located at 2/3 height of the dam. As plotted in Fig. 5, the distributions of the sedimentations calculated with the three models are similar. Figure 6 describes the distribution of the major principle stress of the core-wall. It can be seen that the distribution of the major principle stress obtained form the $\mathrm{E}-\mu$ model is close to that obtained from the E-B model, and stress concentrations related to both models occur in a few regions. But for the double-yield-surface model, all major principle stresses are compressive stresses with smooth distribution, and no stress concentration phenomenon appears. The maximum stress of the core-wall with a magnitude of $1.2494 \mathrm{MPa}$ is small by comparison with the results obtained with other two models, and it appears at the bottom corner of the right bank of the core-wall. Due to the appearance of local stress concentration, the maximum stresses of the core-wall obtained from the E- $\mu$ model and the E-B model, which are 2.0872 MP and 2.2294 MPa respectively, are much larger than that obtained from the double-yield-surface model. The maximum tension strains of the core-wall are listed in Table 3, in which results obtained from the E- $\mu$ model and the E-B model are in good agreement with each other and much greater than that of the double-yield-surface model. As we know, the asphalt concrete is a kind of good plastic material, but Duncan's models can not reflect the dilatancy and cross-effects of compressing and shearing of soils. But, since the plastic strain of soils is taken into account, the double-yield-surface model can describe various 
soil characteristics including pressure hardening, nonlinearity, dilatancy as well as stress-induced anisotropy. Thus, the calculated results got with the double-yield-surface model are more reasonable theoretically than those with Duncan's models. Moreover, the strain distribution of the core-wall obtained with double-yield-surface model is very close to the practical observation results.

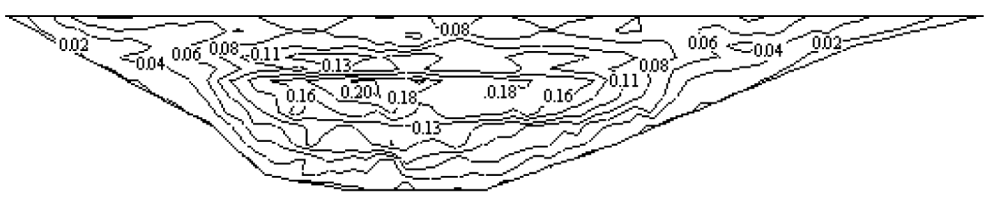

(a) E- $\mu$ model

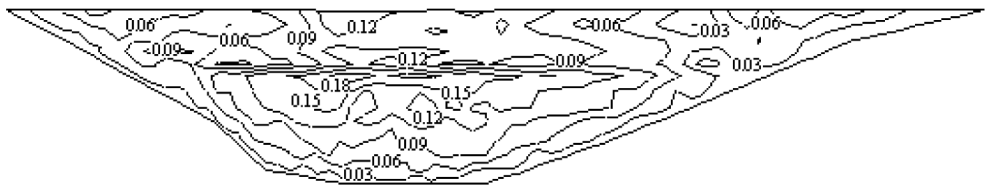

(b) E-B model

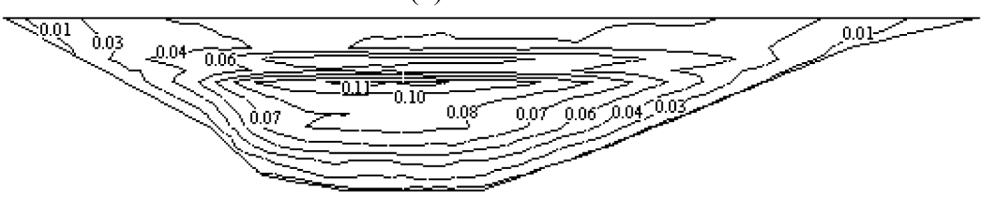

(c) Double-yield-surface model

Fig. 5. Sedimentation distribution of the core-wall after completion (m).

Table 3

Maximum tensile strain of the core wall.

\begin{tabular}{|c|c|c|c|c|c|}
\hline \multirow{2}{*}{$\begin{array}{l}\text { Working } \\
\text { condition }\end{array}$} & \multirow{2}{*}{ Models } & \multirow{2}{*}{$\begin{array}{l}\text { Maximum tensile } \\
\text { strain } \varepsilon_{y}\end{array}$} & \multicolumn{3}{|c|}{ Locations of the max tensile strain $/ \mathrm{m}$} \\
\hline & & & $x$ & $y$ & $z$ \\
\hline \multirow{3}{*}{ After completion } & E- $\mu$ model & 0.0133 & 0.40 & 622.00 & 135.11 \\
\hline & E-B model & 0.0132 & 0.40 & 633.50 & 145.20 \\
\hline & DYS model & 0.0058 & -0.40 & 596.85 & 108.50 \\
\hline \multirow{3}{*}{ After impoundment } & E- $\mu$ model & 0.0073 & -0.40 & 642.00 & 130.50 \\
\hline & E-B model & 0.0077 & -0.40 & 627.68 & 81.57 \\
\hline & DYS model & 0.0027 & 0.40 & 598.62 & 98.83 \\
\hline
\end{tabular}

Note: Strain is positive in tension and negative in compression.

When the water is impounded to the normal height of the dam, the maximum displacement of the dam along the direction of the river is $0.0766 \mathrm{~m}$ with the $\mathrm{E}-\mu$ model, $0.1376 \mathrm{~m}$ with the E-B model and $0.0653 \mathrm{~m}$ with the double-yield-surface model. The results of the $\mathrm{E}-\mu$ model is close to that of the double-yield-surface model but less than that of the E-B model, which is different with the results after completion. Figure 7 


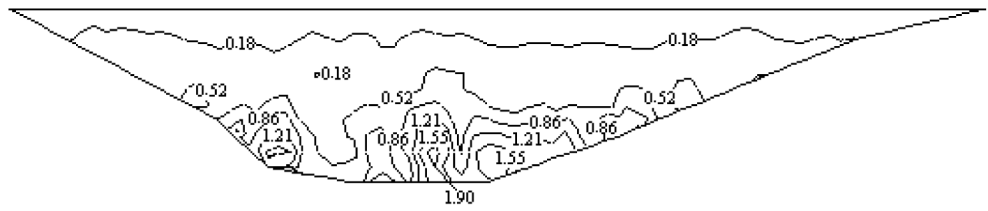

(a) E- $\mu$ model

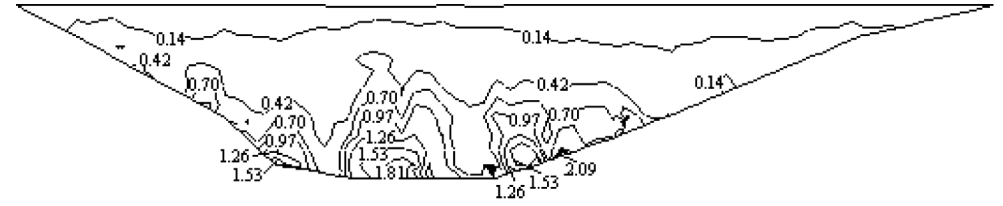

(b) E-B model

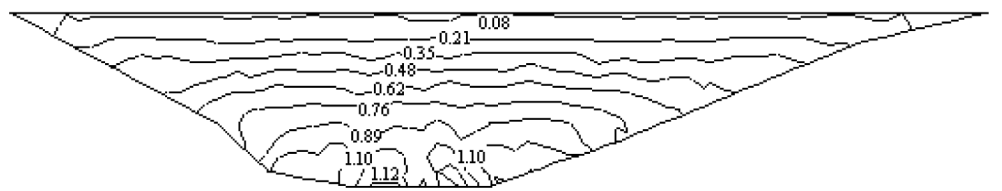

(c) Double-yield-surface model

Fig. 6. Distribution of the major principle stress of the core-wall after completion (MPa).

illustrates the displacement distribution of the highest dam profile along the direction of river. After the water storage, the horizontal displacement of the dam increases proportionally with the height due to the water pressure. This tendency is consistent with the distribution of the water pressure. The maximum horizontal displacements got from the E-B model and double-yield-surface model are both at middle point of the dam crest. The calculated maximum sedimentation is $0.1894 \mathrm{~m}$ with the E- $\mu$ model, $0.1596 \mathrm{~m}$ with the E-B model and $0.0543 \mathrm{~m}$ with the double-yield-surface model.

The distribution of the compressive stress of the highest dam profile is shown in Fig. 8, in which the distributions obtained from the three models are very similar. Table 2 displays the maximum vertical compressive stress of the dam. After the water storage, the calculated maximum major principle stresses of the dam are $1.7994 \mathrm{MPa}$ with the E- $\mu$ model, $1.5673 \mathrm{MPa}$ with the E-B model and $1.4552 \mathrm{MPa}$ with the double-yield-surface model, respectively, and all of them occur at the contact region between the dam bottom and the core-wall. The maximum minor principle stress is $0.8772 \mathrm{MPa}$ with the $\mathrm{E}-\mu$ model, $0.9828 \mathrm{MPa}$ with the E-B model and $0.5491 \mathrm{MPa}$ with the double-yield surface model. In the distribution of minor principle stress, the tension stress got from the double-yield-surface model is very small, only $0.1391 \mathrm{MPa}$. It is different from the results at the dam completion that the maximum tension stress of the minor principle stresses reduces from $0.4941 \mathrm{MPa}$ to $0.3993 \mathrm{MPa}$ with the E- $\mu$ model, but increases from $0.5755 \mathrm{MPa}$ to $0.6394 \mathrm{MPa}$ with the E-B model. This phenomenon is related with the stress and deformation of the core-wall. 


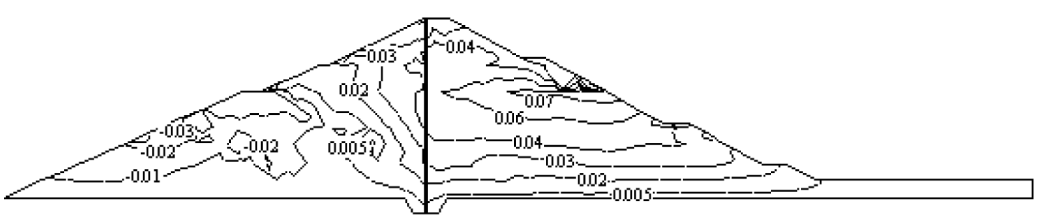

(a) E- $\mu$ model

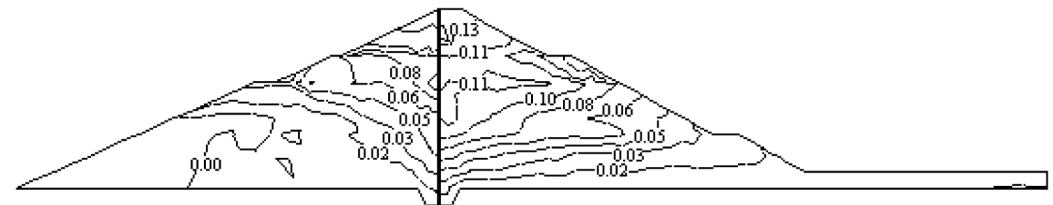

(b) E-B model

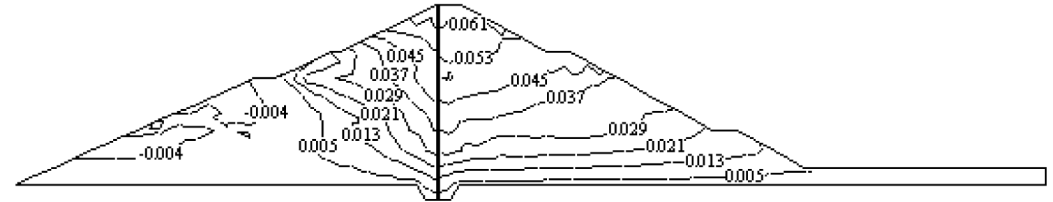

(c) Double-yield-surface model

Fig. 7. Displacement distribution of the highest dam profile along the river direction (m).

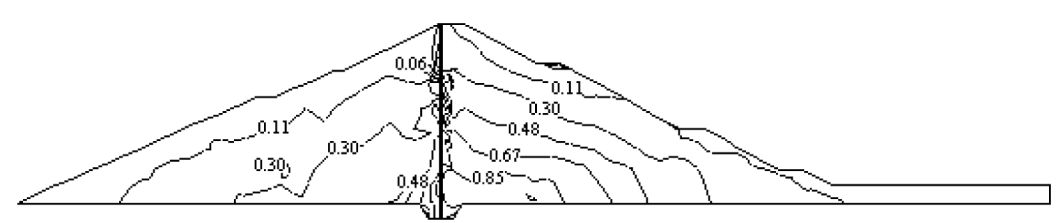

(a) E- $\mu$ model

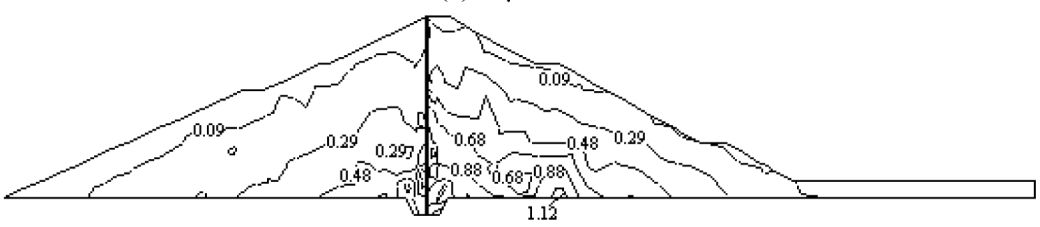

(b) E-B model

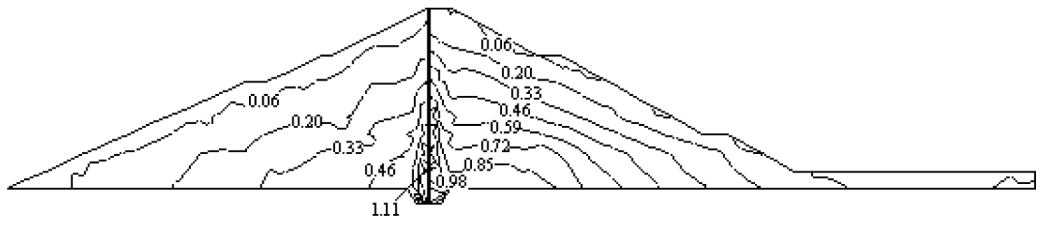

(c) Double-yield-surface model

Fig. 8. Compressive stress distribution of the highest dam profile. 
The maximum displacement of the core-wall along the direction of the river is $0.0618 \mathrm{~m}$ with the E- $\mu$ model, $0.1376 \mathrm{~m}$ with the E-B model and $0.0653 \mathrm{~m}$ with the double-yield-surface model, when the water is impounded to the normal high height. The displacement distribution along the river direction is shown in Fig. 9, and it is coincide with the distribution of water pressure. The displacements of the highest profile of the core-wall for different height are depicted in Fig. 10. It is shown that the displacements got from the $\mathrm{E}-\mu$ model are close to that from the double-yield-surface model. The distribution of the major principle stress of the core-wall is plotted in Fig. 11. The maximum major principle stresses calculated with the three models are 1.4689 MPa, 2.1987 MPa and 1.1014 MPa, respectively. With the E-B model, the stress concentration appearing at the contact region between the dam and the core-wall directly results in the occurrence of the large tension stress. In contrast, the stress concentration phenomenon is not significant for the major principle stress obtained from the $\mathrm{E}-\mu$ model. Comparing with the results got with the former two models, the major principle stresses with the double-yield-surface model are much small and the stresses gradually decrease along the height. Its stress distribution is relatively uniform and reasonable. The calculated tension strains of the core-wall, as shown in Table 3, have a similar trend with stresses. The maximum tension strain from the E-B model is the largest one, 0.0198, but the results from the E- $\mu$ model and double-yield-surface mode, which is close to the observation data, are 0.0073 and 0.0027 , respectively.

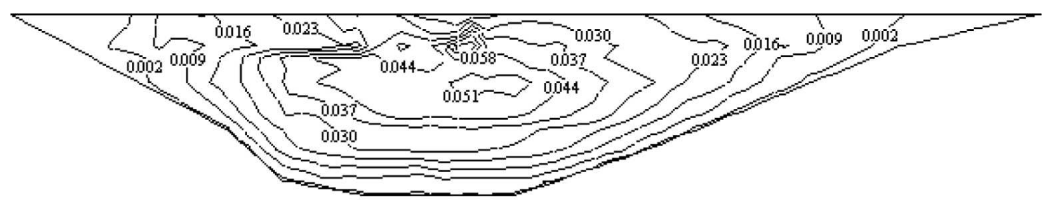

(a) E- $\mu$ model

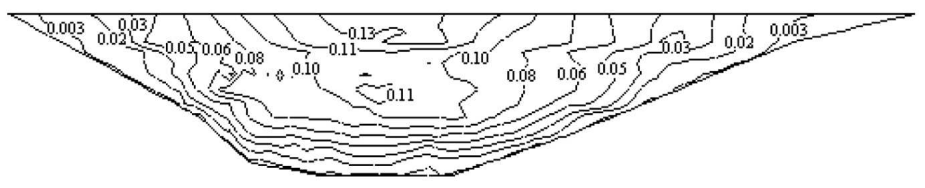

(b) E-B model

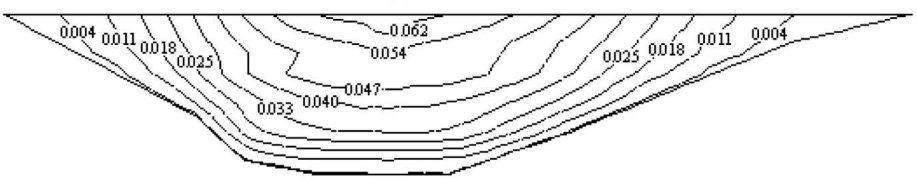

(c) Double-yield-surface model

Fig. 9. Displacement distribution of the core-wall along the river direction after water impounding.

From all the above analysis, we can conclude, in the stress analysis of the asphalt concrete core-wall, the results obtained from the double-yield-surface model which 


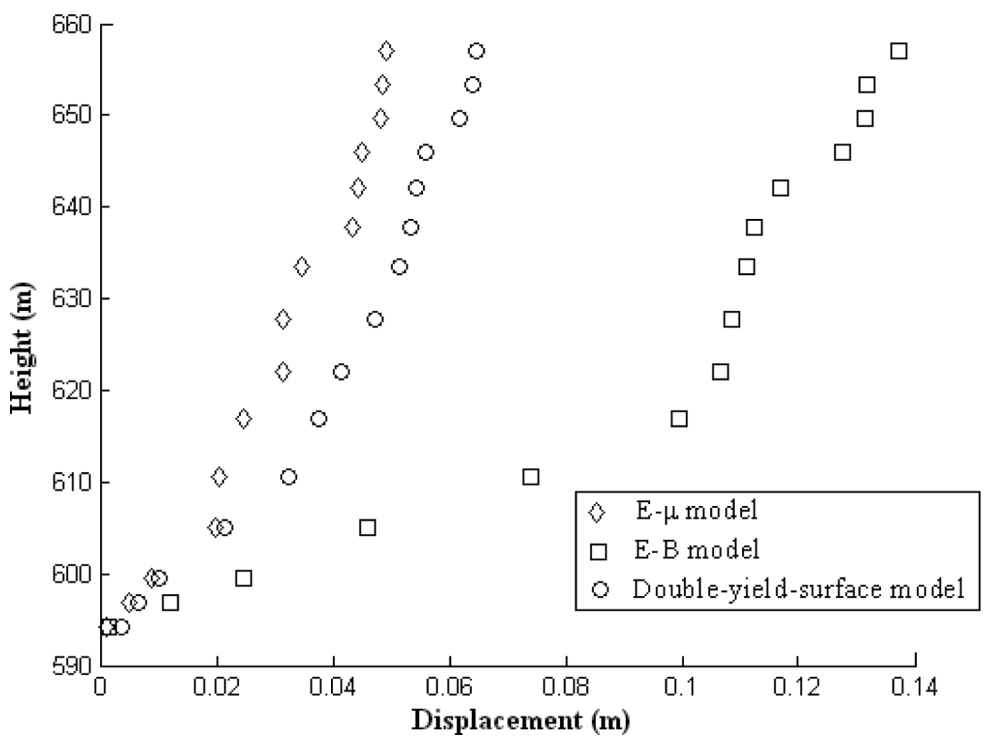

Fig. 10. Displacements of the highest profile of the core-wall for different height (m).

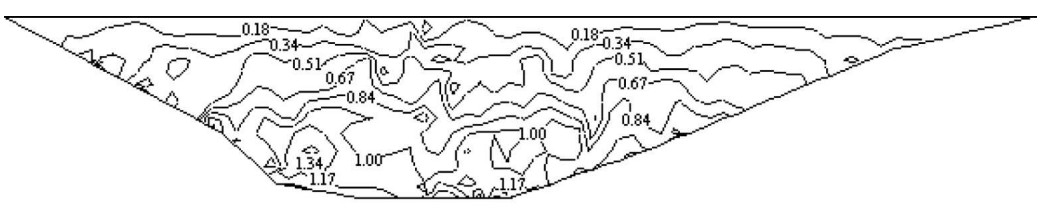

(a) E- $\mu$ model

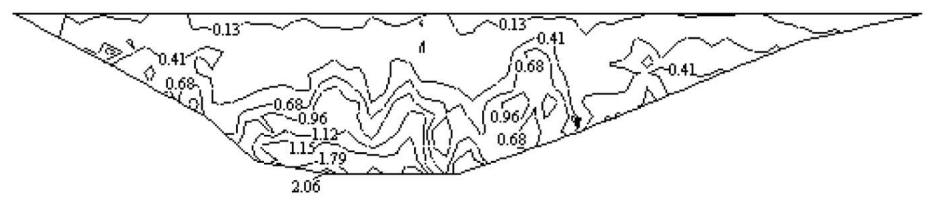

(b) E-B model

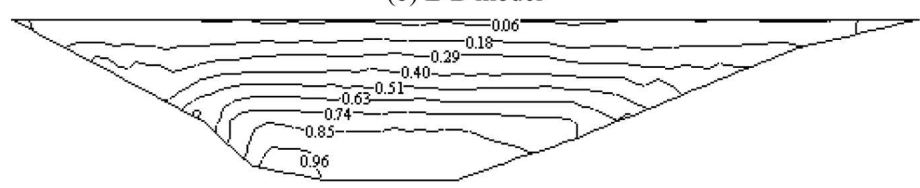

(c) Double-yield-surface model

Fig. 11. Distribution of the major principle stress of the core-wall after water impounding (Mpa). 
considering the plastic strains are more reasonable. The results obtained from the E-B model are not good, especially for those calculated during the water impounding.

\section{Conclusion}

In this paper, the nonlinear static behavior of a practical dam with asphalt concrete core-wall was analyzed with three constitutive models, i.e. the Duncan E- $\mu$ model, the Duncan E-B and the double-yield-surface model. The principal conclusions are summarized below.

1. For the stress analysis of the dam, the results including maximum stress and stress distribution with the three models are consistent. During the sedimentation calculation of the dam, although the obtained sedimentation distribution with the three models are same, the results got from the Duncan E- $\mu$ model and the Duncan E-B model which are based on the soil stress-strain test curve fitting method are closer to the actual observations.

2. As to the deformation analysis of the asphalt concrete core-wall, the displacement distributions of the three models are similar. The sedimentation got from the double-yield-surface mode is less than the results got from the other two models. Moreover after the water impoundment, the displacement along the river direction calculated from the Duncan E- $\mu$ model is close to the result of the double-yieldsurface model but less than the result of the Duncan E-B model.

3. In the stress analysis of the asphalt concrete core-wall, after the dam completion, the stress concentration emerges in the stress distributions of the two Duncan models, which not only results in a larger maximum stress of the core-wall but also influence the stress distribution of the dam. When the water is impounded into the high height, the stress concentration still exists in the results with the Duncan E-B model, but the results obtained from the Duncan E- $\mu$ model are more reasonable relatively.

4. The stress results of the core-wall obtained from the double-yield-surface model are obviously different from those obtained from the other two models. The displacement distribution and stress distribution of the core-wall got from double-yieldsurface model are not only reasonable but also close to the observation data, since the model considered the plastic strain which can describe characteristics of soils including pressure hardening, nonlinearity, dilatancy as well as stress-induced anisotropy.

\section{AKNOWLEDGEMENTS}

This work is supported by National Natural Science Foundation of China (11002106), National Natural Science Foundation of Shannxi Province (2009JQ1008), and the Special Fund for Basic Scientific Research of Central Colleges, Chang'an University (CHD2009JC074). The authors are grateful for this financial support. 


\section{REFERENCES}

1. H. Karre, Asphalt Concrete Cores for Embankment Dams, Norwegian Geotechnical Institute, Publication No. 201, 1993.

2. F.L. Roberts, L.N. Mohammad, L.B. Wang, History of hot mix asphalt mixture design in the United States, J. Mater. Civ. Eng., 14(4), 279-293, 2002.

3. B.L. Zhu, Z.J. Shen, Computational Soil Mechanics. Shanghai, Shanghai Scientific and Technical Publishers, 1990.

4. J.M. Duncan, C.T. Chang, Non-linear analysis of stress and strain in soils, J. Soil Mech. Found. Div., 96(5), 1629-1653, 1970.

5. J.M. Duncan, P. Byrne, K.S. Wong, P. Marby, Strength, Stress-strain and bulk modulous parameters for finite emement analysis of stress and movements in soils masses. Pep. No. UCB/GT/80-01, Univ. of California, Berkekey, Calif, 1980.

6. A.N. Schofield, C.P. Wroth, Critical State Soil Mechanics, McGraw-Hill, New York, 1968.

7. K.H. Roscoe, J.B. Burland, On the generalized stress-strain behaviour of wet clay. Cambridge University Press, 535-609, 1968.

8. Z.J. Shen, J.P. WANG, Stress and strain analysis of Hengshan reservoir rock-fill dam, J. Hydr. 4, 59-65, 1990.

9. C.B. Wu, Q. Yan, Y. Zhang, The Application of APDL in $3 D$ non-linear finite element analysis of concrete face rock-fill dam, Proceedings of the 2010 Asia-Pacific Power and Energy Engineering Conference, Chengdu, April, 2010.

10. A. Frutuoso, A.P. Assis, M.M. Farias, P. FaLCĂo, Numerical analysis of concrete face rockfill dam under three-dimensional conditions, Proceedings of the International Symposium on Dams in the Societies of the 21st Century, ICOLD-SPANCOLD - Dams and Reservoirs, Societies and Environment in the 21 st Century, Spain, June, 2006.

11. J. Wang, J.J. Pan, B. Hunng, Q. Chen, Settling behaviors of the highest Shuibuya concrete faced rock-fill dam, J. Hydr. Eng. 29(4), 160-166, (2010).

12. W.B. WANG, H. KAARE, Cyclic Behavior of Asphalt Concrete Used as Impervious Core in Embankment Dams, J. Geotech. Geoenviron. Eng., 137 (5), 536-544, 2011.

13. S. Feizi-Khankandi, A.A. Mirghasemi, A. Ghalandarzadeh, K. Hoeg, $2 D$ Nonlinear Analysis of Asphaltic Concrete - Core Embankment Dams, The 12th International Conference of International Association for Computer Methods and Advances in Geomechanics, Goa, India, October, 2008.

14. C.Y. FANG, Z.Z. LiU, Stress-strain analysis of Aikou rockfill dam with asphalt-concrete core, Journal of Rock Mechanics and Geotechnical Engineering, 3(2), 186-192, 2011.

15. N. Janbu, Soil compressibility as determined by oedometer and triaxial test, Proceedings of The European Conference On Soil Mechanics And Foundation Engineering, Weisbaden, July, 1963.

Remarks on the paper should be sent to the Editorial Office no later than March 30, 2013
Received August 31, 2012 revised version November 25, 2012 